\title{
Effect of lipopolysaccharide on toll-like receptor-4 signals in mouse cancer cells
}

\author{
Dana $\mathrm{N}^{1}$, Javanmard $\mathrm{SH}^{2}$, Vaseghi $\mathrm{G}^{3}$ \\ Isfahan Cardiovascular Research Centre, Department of Pharmacology, Cardiovascular Research Institute, \\ Isfahan University of Medical Sciences, Isfahan, Iran. golnazvaseghi@yahoo.com
}

\begin{abstract}
BACKGROUND: Recent findings showed that activated TLR signals on cancer cells might promote cancer progression. This study was designed to explore the influence of Toll-like receptor 4 (TLR4) agonist lipopolysaccharides (LPS) on mouse melanoma and breast cancer cell proliferation and their TLR4 signalling.

METHODS: Mouse melanoma cell line (B16F10) and breast cancer cell line (4T1) were taken as models. They were treated with LPS $(0,1.25,2.5,5,7.5,10 \mu \mathrm{g} / \mathrm{ml})$ for $4,16,24,48 \mathrm{~h}$ and MTT assay was done. The expression of TLR4, MyD88, NF-KB mRNA was detected by quantitative real time-polymerase chain reaction method quantitatively.

RESULTS: Ultra-pure LPS at $5 \mu \mathrm{g} / \mathrm{ml}$ concentration increased significantly B16F10 cell viability 24 hour after stimulation, but not in 4T1 cell. The mRNA levels of TLR4, MyD88 and NF-KB were significantly up-regulated in both cell lines by stimulating the cells at $5 \mu \mathrm{g} / \mathrm{ml}$ LPS.

CONCLUSIONS: Our data demonstrated that B16F10 and 4T1 cells are responsive to LPS, but their responses are time and dose dependent. These results provide new ways to understand the TLR4 signalling in tumour cells (Fig. 2, Ref. 24). Text in PDF www.elis.sk.

KEY WORDS: cancer, LPS, mouse, TLR4 signalling, melanoma.
\end{abstract}

\begin{abstract}
Abbreviations: DMEM - Dulbecco's Modified Eagle's medium, ELISA - enzymelinked immunosorbent assay, LPS - Lipopolysaccharide, MTT - 3-(4,5-dimethylthiazol-2-yl)-2.5-diphenyl-2H-tetrazolium bromide, MyD88 - myeloid differentiation primary-response gene 88 , NF- $\kappa \mathrm{B}$ - Nuclear factor kappa-lightchain-enhancer of activated B cells, RPMI - Roswell Park Memorial Institute, QRT-PCR - Quantitative real-time reverse transcriptase-polymerase chain reaction, TLR4,Toll-like receptor-4, VEGF - vascular endothelial growth factor
\end{abstract}

\section{Introduction}

Toll-like receptors (TLRs) are the class of proteins (1) that recognize microbial/pathogen-associated molecular patterns (2). Given the ability of TLRs to recognize a large number of pathogenassociated ligands, they activate both the innate and adaptive immu-

${ }^{1}$ Applied Physiology Research Centre, Cardiovascular Research Institute, Isfahan University of Medical Sciences, Isfahan, Iran, ${ }^{2}$ Department of Physiology, Applied Physiology Research Centre, Cardiovascular Research Institute, Isfahan University of Medical Sciences, Isfahan, Iran, and ${ }^{3}$ Isfahan Cardiovascular Research Centre, Department of Pharmacology, Cardiovascular Research Institute, Isfahan University of Medical Sciences, Isfahan, Iran

Address for correspondence: G. Vaseghi, Cardiovascular Research Centre, Isfahan University of Medical Sciences, Hezar-Jarib Avenue, 8167636954, Isfahan, Iran.

Phone: +98.313 .6692836$

Acknowledgments: This article was derived from $\mathrm{PhD}$ thesis in the Isfahan University of Medical Sciences (No.394617). Ethical approval number IR.MUI.REC.1394.3.617.mm nity (3). TLR4, the first mammalian TLR identified, recognizes the cell wall of Gram-negative bacterial lipopolysaccharide (LPS) (4).

It has been demonstrated that upon infection, LPS induced up-regulation of TLR4. The TLR4 pathway signalling leads to an increased myeloid differentiation primary-response gene 88 (MyD88) activation, which enhances the translocation of NF- $\mathrm{BB}$ to the nucleus, subsequently NF- $\mathrm{kB}$ binds to target genes promoter and leads to tumour genesis (5-7).

Recent findings showed that functional TLRs are expressed not only on immune cells, but also on cancer cells. TLR4 activation upon chronic infection has been accepted as one of the leading cause of inflammation -induced cancer. Thus, infection is a major cause of human cancer in up to one-fifth of all cases $(8,9)$. It also enhances cancer metastasis (10).

Cancer cells show different behaviours in their signalling from each other, some studies showed that activated TLR4 signalling pathway plays proliferative and anti-apoptotic roles in cancer cells, however, the results are inconclusive (11).

Mouse melanoma (B16F10) and mouse breast cancer (4T1) cell lines are widely used as a model for studying many aspects of cancer biology, which can be extrapolated to human malignancies $(12,13)$.

\section{Objectives}

The aim of this study was to investigate the effect of ultra-pure LPS, a specific TLR4 ligand, on signal transduction pathway of these two mouse cancer cell lines. 


\section{Materials and Methods}

\section{Cells and Reagents}

The mouse melanoma cell line (B16F10) and mouse breast cancer cell line (4T1) were obtained from the National Cell bank of Iran (affiliated to Pasteur Institute, Tehran, Iran). The B16F10 cells were cultured in Dulbecco's Modified Eagle's medium (DMEM) and the 4T cells were cultured in RPMI (Roswell Park Memorial Institute) 1640 medium in a humidified atmosphere of $5 \% \mathrm{CO}_{2}$. All media were supplemented with $10 \%$ foetal bovine serum (FBS), HEPES, and penicillin/streptomycin. All cell culture materials were from Gibco, USA. LPS-EB ultrapure that is lipopolysaccharide from E. coli 0111:B4 was purchased from Invivogen (San Diego, CA).

\section{Cell proliferation}

The proliferation of B16F10 and 4T1 cells was evaluated by seeding $8 \times 10^{3}$ cells/well in 96 well, flat-bottoms, microtiter plates. Cell growth in the presence or absence of ultra-pure LPS $(0,1.25,2.5,5,7.5,10 \mu \mathrm{g} / \mathrm{ml})(7,14)$ was measured after 4,16 , $24,48 \mathrm{~h}$ treatment. The final volume of complete culture medium was $200 \mu 1$.

The metabolic activity in each well was determined by 3-(4,5-dimethylthiazol-2-yl)-2.5-diphenyl-2H-tetrazolium bromide (MTT) assay and compared to the untreated cells. Plates were read by using an enzyme-linked immunosorbent assay (ELISA) plate reader (ELX 800-BioTek-USA) at $570 \mathrm{~nm}$ with a reference wavelength of $630 \mathrm{~nm}$ (15). The cell viability was determined by the following formula:

$\%$ Cell viability $=($ Mean absorbance in test wells/Mean absorbance in control wells) $\times 100$

Quantitative real-time reverse transcriptase-polymerase chain reaction ( $Q R T-P C R)$

Since LPS-EB Ultrapure is a specific TLR4 agonist, we used it in this study to activate the TLR4 signalling. The cells were stimulated $24 \mathrm{~h}$ with or without of LPS $(5 \mu \mathrm{g} / \mathrm{ml})$. Total cellular RNA was extracted GeneJET RNA purification kit (Thermo Scientific, (EU) Lithuania). One microgram of total RNA was utilized for the reverse transcriptase reaction. cDNA was synthesized using RevertAidTM Reverse Transcriptase (Fermentas, Vilnius, Lithuania) with oligo-dT primers.

The PCR assay began with one cycle of denaturation at $95^{\circ} \mathrm{C}$ for $5 \mathrm{~min}$, followed by 45 cycles of $95^{\circ} \mathrm{C}$ for $1 \mathrm{~min}, 1-\mathrm{min}$ annealing period of $54^{\circ} \mathrm{C}$ for $T L R 4, M y D 88, N F-\kappa B$ and beta actin (as internal control). A second 1-min annealing period was completed at $72^{\circ} \mathrm{C}$ before a final extension at $72{ }^{\circ} \mathrm{C}$ for $10 \mathrm{~min}$.

RT-PCR analyses were performed using the following primer sets:

MyD88:

Forward primer (5'-AAGTCTAGGAAGGCCCCAAA-3')

Reverse primer (5'-CTGGGGAGAAAACAGCTGAG-3')

$N F-\kappa B$ :

Forward primer (5'- ACACGAGGCTACAACTCTGC-3'(

Reverse primer (5'- GGTACCCCCAGAGACCTCAT-3')

\section{TLR4:}

Forward primer) 5'- AGTGGCTGGATTTATCCAGGTGTG-3'(

Reverse primer)5'- TTGAGAGGTGGTGTAAGCCATGCC-3'(

$\beta$-actin:

Forward primer) 5'-TGT TAC CAA CTG GGA CGA CAT GGA 3'(

Reverse primer) 5'- CCG CTC GTT GCC AAT AGT GAT GAC - $3^{\prime}($

The qRT-PCR cDNA products were verified using a $2 \%$ agarose gel. (The quality of RNA was verified by spectrophotometer and gel electrophoresis.)

Quantitative RT-PCR was performed using specific primers for TLR4, MyD88, NF- $\kappa B$ and beta-actin (as an internal control) mRNAs with the Maxima SYBR Green/ROX qPCR Master Mix (Fermentas, Vilnius, Lithuania) and run on the Rotor-gene 6000(Qiagen, Hilden, Germany).
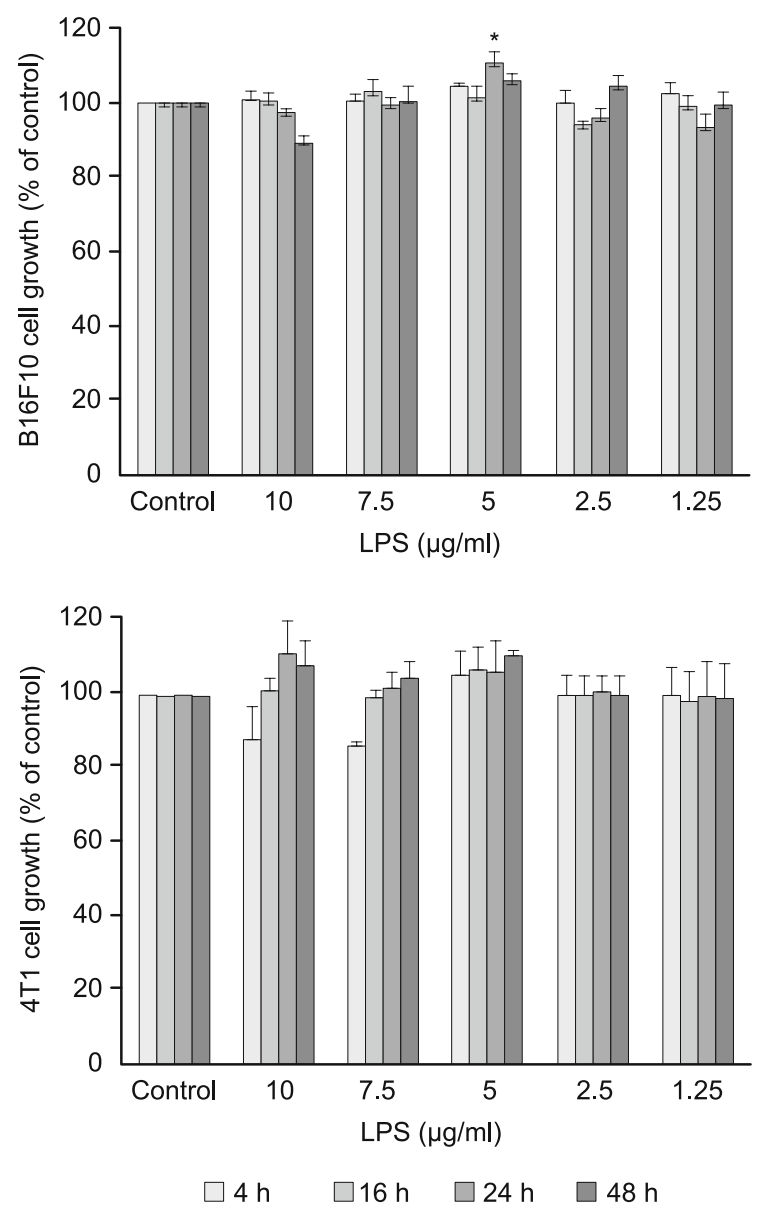

Fig. 1. Effects of LPS treatment on B16F10 and 4T1cell viability. The cells were exposed to various concentrations of LPS $(0,1.25,2.5,5$, $7.5,10 \mu \mathrm{g} / \mathrm{ml}$ ) for $4,16,24,48 \mathrm{~h}$. After treatment MTT assay was done. $* p<0.05$ compared with negative control. The data are expressed as mean \pm SEM. 


\section{8-601}

\section{Statistical analysis}

The experiments were performed in triplicate and replicated two times. At last, one-way analysis of variance (ANOVA) and t-test analysis was performed to analyse the data using the software SPSS 20. Values of $p<0.05$ were considered statistically significant.

\section{Results}

Effect of lipopolysaccharide on B16F10 and $4 T 1$ cell lines viability

The MTT assay was used to determine the effects of TLR4 stimulation on B16F10 and 4T1 cell proliferation. The cells were exposed to culture medium or ultra-pure LPS $(0,1.25,2.5,5,7.5$, $10 \mu \mathrm{g} / \mathrm{ml}$ ) for $4,16,24$ and $48 \mathrm{~h}$.

LPS did not influence the proliferation rate in B16F10 cell line tested after 4, 16 and $48 \mathrm{~h}(\mathrm{p}>0.05)$ (Fig. 1). After 24 hours of incubation, only LPS in $5 \mu \mathrm{g} / \mathrm{ml}$ dose significantly increased B16F10 cell viability $(\mathrm{p}<0.005)$ (Fig. 1). LPS did not significantly affect the proliferation rate of $4 \mathrm{~T} 1$ cells under different LPS-treated conditions $(p>0.05)$.

LPS up regulates the expression of TLR4, MyD88 and NF- $\kappa B$ in B16F10 and $4 T 1$ cell lines

Because LPS at concentration of $5 \mu \mathrm{g} / \mathrm{ml}$ significantly increased the cell viability, we chose this concentration for mRNA expression test. As shown in Figure 2, the expression of TLR4 mRNA in melanoma and 4T1 cell line was analysed by qRT-PCR. TLR4 mRNA expression was significantly up-regulated in B16F10 (p = $0.003)$ and $4 \mathrm{~T} 1$ cells $(\mathrm{p}=0.022) 24 \mathrm{~h}$ after stimulation.

To investigate the downstream molecular events of LPS-TLR4 signalling in these cells, we examined the effect of LPS on the MyD 88 mRNA expression. MyD 88 mRNA expression was significantly up regulated in both $\mathrm{B} 16 \mathrm{~F} 10(\mathrm{p}=0.005)$ and 4T1cells $(\mathrm{p}$ $=0.033$ ), following LPS treatment. Although the mRNA expression of NF- $\mathrm{KB}$ was significantly enhanced in B16F10 $(p=0.031$ and $4 \mathrm{~T} 1(\mathrm{p}<0.001)$.

\section{Discussion}

In this study, we tried to evaluate the effects of different concentrations of ultra-pure LPS $(0,1.25,2.5,5,7.5,10 \mu \mathrm{g} / \mathrm{ml})$ in different times $(4,16,24,48 \mathrm{~h})$ on the cell viability of B16F10 and 4T1 cell lines and their TLR4 signal transduction pathway.

Results indicated that LPS at the concentration of $5 \mu \mathrm{g} / \mathrm{ml}$ significantly increased proliferation in B16F10 cell after 24 hours. However, other doses and times, LPS did not significantly altered melanoma cell viability.

LPS treatment in 4T1 cell increased the cell viability compared to the control after treatment, but results were not significant. Overall, the results indicated that LPS has a distinct effect on cell proliferation and viability depending on the time, concentration and type of cell used.

For example, LPS did not influence the proliferation rate in any of melanoma cell lines tested such as SKMEL-28, BN1,
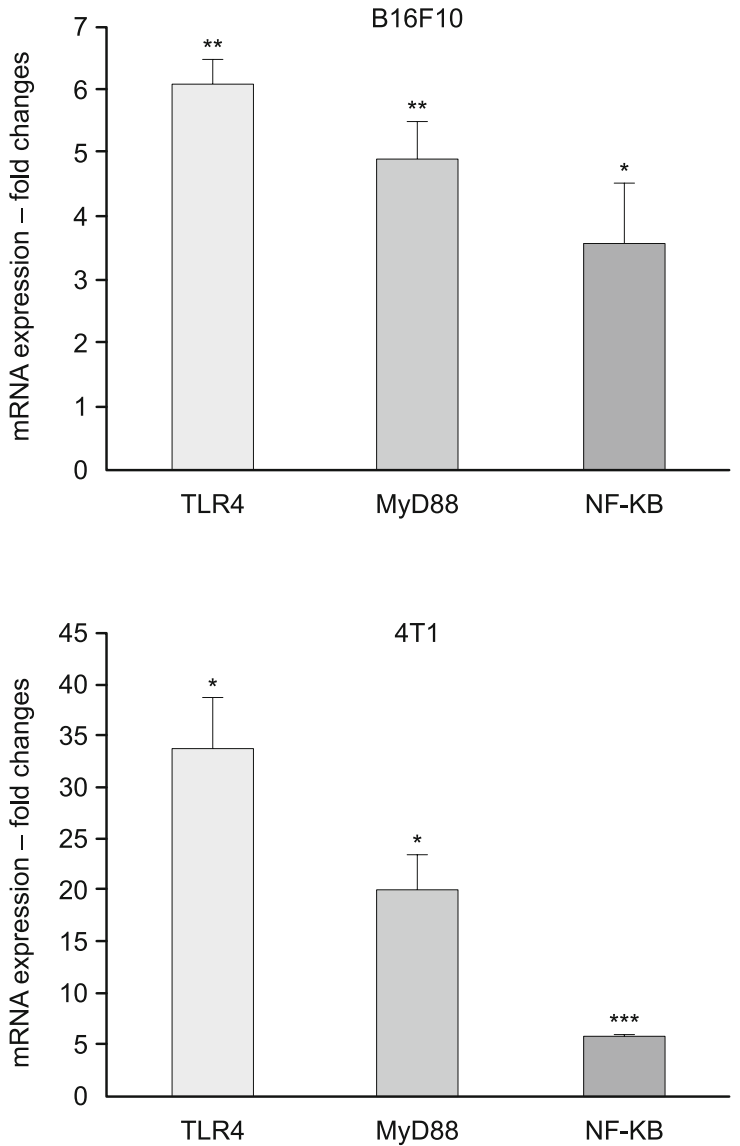

Fig. 2. Effects of LPS treatment on expression of TLR4, MyD88 and NF- $\kappa B$. The cells were incubated with LPS $(5 \mu \mathrm{g} / \mathrm{ml})$ for $24 \mathrm{~h}$. mRNA expression was measured using QRT-PCR. * $p<0.05$; ** $p<0.01$; $* * * \mathbf{p}<0.001$ compared with negative control. Each graph has been represented as mean \pm SEM. * $p<0.05$.

9923P, 9923M cell lines, while the other studies showed that LPS promoted proliferation of TLR $4^{+}$melanoma cells (14). In the other study, knockdown of TLR4 in human breast cancer cell line (MDA-MB-231) significantly reduced proliferation and survival of tumour cell proliferation (16). This is true for the other cancer cell lines such as human oesophageal and oral cancer cells (17).

This is the first study to our knowledge that examines the effect of ultra-pure LPS on mouse melanoma cell line (B16F10) and mouse breast cancer cell line (4T1) proliferation.

The link between TLR signalling and cell cycle control has not been explored yet $(18,19)$. Activation of TLR4 might be related to tumour growth as it regulates the expression of vascular endothelial growth factor $(V E G F)$ mRNA in human breast cancer cells. The stimulation of TLR4 by LPS promotes tumour genesis and the development of metastatic lesions in the liver of mice (20).

Pidgeon et al showed that during tumour surgery, when LPS is introduced in mice, quickly prompted inflammatory reactions in immune system and tumour metastasis increased (10). 
To better understand the mechanisms involved in LPS effects, we compared TLR4, MyD88 and NF- $\kappa B$ gene expression with or without LPS treatment. Because LPS at concentration of $5 \mu \mathrm{g} / \mathrm{ml}$ significantly increased the cell viability, we chose this concentration for mRNA expression test.

The results of qRT-PCR assay showed that B16F10 and 4T1 cell lines expressed TLR4, MyD88 and Nf- $\kappa \mathrm{B}$ significantly more than the control.

LPS binding to TLR4 activates MyD88-dependent signalling. Internalization of the LPS-TLR4 complex activates TIR-domaincontaining adaptor protein inducing IFN $\beta$ (TRIF)-mediated signalling (MyD88-independent signalling) in the endosome $(21,22)$.

MyD88-deficient mice were shown to be resistant to LPS-induced septic shock, and MyD88-deficient macrophages failed to produce proinflammatory cytokines after LPS stimulation, despite the ability to activate NF- $\mathrm{BB}$ (23).

$\mathrm{NF}-\kappa \mathrm{B}$ signalling promotes inflammation and cell proliferation through induction of inflammatory cytokines and inhibition on both death receptor pathway of apoptosis and mitochondrial pathway of apoptosis (24).

In this study, stimulation of TLR4 by specific agonist, ultrapure LPS increased $N F-\kappa B$ expression.

In conclusion, the present study provides evidence that LPS can stimulate TLR4 signalling in both mouse cancer cell lines. It should be concluded that B16F10 and 4T1 could be used as a good model for in vitro and in vivo TLR4 signalling research.

\section{References}

1. Stewart EA, Wei R, Branch MJ, Sidney LE, Amoaku WM. Expression of Toll-like receptors in human retinal and choroidal vascular endothelial cells. Exp Eye Res 2015; 138: 114-123. doi: 10.1016/j. exer.2015.06.012.

2. Janeway CA, Medzhitov R. Innate immune recognition. Annu Rev Immunol.2002; 20: 197-216. doi: 10.1146/annurev.immunol.20.083001.084359.

3. Akira S, Takeda K. Toll-like receptor signalling. Nat Rev Immunol 2004; 4 (7): 499-511. doi: 10.1038/nri1391.

4. Akira S, Takeda K, Kaisho T. Toll-like receptors: critical proteins linking innate and acquired immunity. Nat Immunol 2001; 2 (8): 675-680. doi: $10.1038 / 90609$.

5. Kawai T, Akira S. The role of pattern-recognition receptors in innate immunity: update on Toll-like receptors. Nat Immunol 2010; 11 (5): 373384. doi: $10.1038 /$ ni. 1863 .

6. Fukata M, Chen A, Vamadevan AS et al. Toll-like receptor-4 promotes the development of colitis-associated colorectal tumors. Gastroenterology 2007; 133 (6): 1869-1881. doi: 10.1053/j.gastro.2007.09.008.

7. Goto Y, Arigami T, Kitago M et al. Activation of Toll-like receptors 2, 3 , and 4 on human melanoma cells induces inflammatory factors. Mol Cancer Ther 2008; 7 (11): 3642-3653. doi: 10.1158/1535-7163.MCT-08-0582.

8. Siegel R, Ma J, Zou Z, Jemal A. Cancer statistics, 2014. CA Cancer J Clin 64 (1): 9-29. doi: 10.3322/caac.21208.
9. Kuper H, Adami HO, Trichopoulos D. Infections as a major preventable cause of human cancer. J Intern Med 2000; 248 (3): 171-183. http: //www.ncbi.nlm.nih.gov/pubmed/10971784.

10. Pidgeon GP, Harmey JH, Kay E, Da Costa M, Redmond HP, Bouchier-Hayes DJ. The role of endotoxin/lipopolysaccharide in surgically induced tumour growth in a murine model of metastatic disease. Br J Cancer 1999; 81 (8): 1311-1317. doi: 10.1038/sj.bjc.6694369.

11. Oblak A, Jerala R. Toll-like receptor 4 activation in cancer progression and therapy. Clin Dev Immunol 2011; 2011: 609579. doi: $10.1155 / 2011 / 609579$.

12. Bobek V, Kolostova K, Pinterova D et al. A clinically relevant, syngeneic model of spontaneous, highly metastatic B16 mouse melanoma. Anticancer Res 2010; 30 (12): 4799-4803. http: //www.ncbi.nlm.nih.gov/ pubmed/21187455.

13. Pulaski BA, Ostrand-Rosenberg S. Mouse $4 \mathrm{~T} 1$ breast tumor model. Curr Protoc Immunol. 2001; Chapter 20: Unit 20.2. doi: 10.1002/0471142735.im2002s39.

14. Molteni M, Marabella D, Orlandi C, Rossetti C. Melanoma cell lines are responsive in vitro to lipopolysaccharide and express TLR-4. Cancer Lett 2006; 235 (1): 75-83. doi: 10.1016/j.canlet.2005.04.006.

15. Dana N, Javanmard SH, Rafiee L. Antiangiogenic and antiproliferative effects of black pomegranate peel extract on melanoma cell line. Res Pharm Sci 10 (2): 117-124. http: //www.ncbi.nlm.nih.gov/ pubmed/26487888.

16. Yang H, Zhou H, Feng P et al. Reduced expression of Toll-like receptor 4 inhibits human breast cancer cells proliferation and inflammatory cytokines secretion. J Exp Clin Cancer Res 2010; 29: 92. doi: 10.1186/17569966-29-92.

17. Gonçalves Márcia, Cappellari Ángelica Regina, Santos Junior André Avelino dos, Macchi Fernanda Souza, Antunes Krist Helen SAPD de et al . Effect of LPS on the Viability and Proliferation of Human Oral and Esophageal Cancer Cell Lines. Braz Arch Biol Technol 2016; 59.

18. Hasan UA, Trinchieri G, Vlach J. Toll-like receptor signaling stimulates cell cycle entry and progression in fibroblasts. J Biol Chem 2005; 280 (21): 20620-20627. doi: 10.1074/jbc.M500877200.

19. Li X, Jiang S, Tapping RI. Toll-like receptor signaling in cell proliferation and survival. Cytokine 2010; 49 (1): 1-9. doi: 10.1016/j. cyto.2009.08.010.

20. Yang H, Wang B, Wang $\mathbf{T}$ et al. Toll-like receptor 4 prompts human breast cancer cells invasiveness via lipopolysaccharide stimulation and is overexpressed in patients with lymph node metastasis. PLoS One 2014; 9 (10): e109980. doi: 10.1371/journal.pone.0109980.

21. Lu Y-C, Yeh W-C, Ohashi PS. LPS/TLR4 signal transduction pathway. Cytokine 2008; 42 (2): 145-151. doi: 10.1016/j.cyto.2008.01.006.

22. Kagan JC, Su T, Horng T, Chow A, Akira S, Medzhitov R. TRAM couples endocytosis of Toll-like receptor 4 to the induction of interferonbeta. Nat Immunol 2008; 9 (4): 361-368. doi: 10.1038/ni1569.

23. Kawai T, Adachi O, Ogawa T, Takeda K, Akira S. Unresponsiveness of MyD88-deficient mice to endotoxin. Immunity 1999; 11 (1): 115-122. http: //www.ncbi.nlm.nih.gov/pubmed/10435584.

24. Hoesel B, Schmid JA. The complexity of NF- $\mathrm{KB}$ signaling in inflammation and cancer. Mol Cancer 2013; 12 (1): 86. doi: 10.1186/14764598-12-86.

Received May 27, 2017. Accepted June 19, 2017. 